\title{
Espanha e o Vice-Reinado do Rio da Prata: a consolidação do Comércio Livre no triênio 1787-1789
}

Manoel Lelo Bellotto

Universidade Estadual Paulista

São Paulo - Brasil

O tema Comércio Livre constitui peça importante na análise histórica das relações entre Espanha e América nos momentos que antecederam ao processo de emancipação das colonias hispano-americanas. Para compreensão da aplicação da sistemática do comércio livre e para percepção dos problemas decorrentes, optou-se por proceder à análise do documento normativo do sistema, isto é, o Reglamento y Aranceles Reales para el Comercio Libre de España a Indias, de 12 de outubro de 1778, e pela demonstração, a partir de dados concretos levantados no Archivo General de Indias, de Sevilla, da prática resultante. A ordenação dos referidos dados, no entanto, restringiu-se ao movimento comercial no sentido América-Espanha, isto é, entre os portos de Buenos Aires e Montevidéo e os portos espanhóis habilitados ao comércio livre pelo Regulamento de 1778, no triênio 1787-1789.

Destina-se o presente artigo a registrar a implantação do comércio livre entre portos de América e de Espanha, habilitados pelo Reglamento y Aranceles Reales para el Comercio Libre de España a Indias, de 12 de outubro de 1778, nos anos de 1787, 1788 e 1789. Foram fixados, na América, os portos de Buenos Aires e de Montevidéo; na Espanha, todos aqueles visitados pelas embarcações procedentes de tais portos, com registro de comércio livre.

Elegeu-se o período de 1787 a 1789 para a realização do presente estudo porque, embora tenha sido regulamentada em outubro de 1778, a instituição do comércio livre iniciou sua consolidação somente a partir do término da guerra de 1779 a 1783, entre Espanha e Inglaterra. ${ }^{1}$ Deve-se considerar, ainda, que a documentação existente no Archivo General de Indias, de Sevilla, referente às relações comerciais entre Espanha e suas colônias americanas durante a vigência do Regulamento de 1778, tem por marco primeiro o ano de $1787 .{ }^{2}$ Explica-se, assim, o balizamento cronológico inicial do presente trabalho. A definição do mencionado período resul-

1 Klein, Herbert S.: "Structure and profitability of royal finance in the Vice-royalty of the Rio de la Plata in 1790”. Hispanic American Historical Review. T. 53, n. 3. Durham, aug. 1973, pág. 441.

2 Archivo General de Indias, Indiferente General, 2441 e 2442. 
tou, ainda, da opção científica frente a um núcleo documental denso: tratase do registro das relações comerciais entre os portos platinos e os habilitados de Espanha, durante os anos supra referidos, em que não ocorrem omissões de dados essenciais do referido tráfico.

Cumpre dizer, ainda, que o presente estudo, ao averiguar a implantação do disposto no Regulamento de 1778 entre portos habilitados de Espanha e América, caracteriza-se por uma abordagem unilateral do processo, por estar restrito à análise das embarcações e mercadorias que, de Montevidéo, demandavam os portos espanhóis. Não se procedeu, portanto, por opção metodológica, ao estudo do giro mercantil completo.

Cabe, finalmente, esclarecer o aparente conflito entre o uso freqüente, no texto, da expressão portos platinos e o exclusivo registro de Montevidéo, como porto exportador. A expressão refere-se, obviamente, aos portos de Buenos Aires e Montevidéo. Hoje, em função da situação política caracterizada pelas repúblicas autônomas da Argentina e do Uruguai, certamente causa estranheza a referência única a ambos os portos, como se apenas a um se reportasse. No entanto, e usando de uma liberdade de linguagem, a nosso ver justificada, é possível evidenciar o caráter de "complexo portuário" aos serviços prestados pelos dois portos à unidade política e administrativa representada pelo então Vice-Reinado do Prata.

Acresçam-se, por outro lado, as dificuldades de acesso ao porto de Buenos Aires, pelo Rio da Prata, ainda presente na década de ' 80 do século XVIII, período de que se ocupa este estudo. Tais dificuldades eram resultado, por um lado, das limitações técnicas das embarcações de longo curso em uso na época, a dependerem exclusivamente do regime de ventos para seu deslocamento; por outro lado, das condições especialíssimas do estuário do Prata, no trecho entre Montevidéo e Buenos Aires. Montevidéo, além de ser um porto seguro para as embarcações de maior porte, ensejava a querena de navios em ponto ideal para tal operação, na Ilha das Gaivotas, defronte da cidade. ${ }^{3}$ Aos riscos que o leito do Rio da Prata oferecia à navegação, representados pelos incontáveis bancos de areia e inúmeros e traiçoeiros canais, a exigirem o concurso de práticos hábeis e adestrados, há de se acrescentar o inconveniente dos "ventos contrários". Trata-se do pampeiro, vento procedente das regiões meridionais da Argentina, que traspassa todo o estuário platino e, através do Uruguai, chega a alcançar o sul do Brasil, sob o nome de minuano.

3 AGI, Buenos Aires, 17. "Instrucción que deben observar los Capitanes Pilotos...destinados al puerto de Montevideo.” Madrid, 5 de dezembro de 1767. 
Tão temido era e tal a sua ação de retardamento da navegação, a reter por meses as embarcações que se introduzissem no Rio da Prata, como testemunha o governador de Montevidéo em 1768, ${ }^{4}$ que esta cidade foi eleita para porto escoador da produção do Vice-Reinado do Prata, sem prejuízo da atuação econômica e da individualidade portuária de Buenos Aires. Efetivamente, tal ocorreu. A aplicação do esquema de liberdade comercial, representado pelo Regulamento de 1778, ensejou a Buenos Aires, pelo menos até o ano de 1795, viver um fértil período de amplo desenvolvimento no comércio internacional, tornando-se o porto platino, em decorrência desse fato, importante fonte de rendas tributárias para a Coroa Espanhola. ${ }^{5}$ A ligação fluvial entre Buenos Aires e Montevidéo era operada por embarcações menores, que transportavam toda a sorte de mercadoria. Havia, ainda, uma variante dessa ligação. Tratava-se da conecção fluvial entre Buenos Aires e a cidade de Colônia, na margem esquerda do Prata, e desta, por terra, a Montevidéo. O tempo médio gasto em ambos os trajetos era, respectivamente, de 5 e 3 dias.

\section{Movimento de embarcações com registro de Comércio Livre}

Transcreve-se, em apêndice, o quadro geral do movimento de embarcações com registro de comércio livre que, saindo do porto de Montevidéo nos anos de 1787,1788 e 1789, demandaram os portos habilitados da Metrópole. ${ }^{6}$ Foi adotado, por critério, relacionar as embarcações que deixaram o Prata, desde a primeira que saiu do porto de Montevidéo no ano de 1787, até a última que o fez no de 1789. Como balizas cronológica, portanto, não foram consideradas as datas de chegada aos portos de destino.

O referido quadro geral tem, ademais, uma outra característica a ressaltar. Cada embarcação tem sua rota devidamente devassada, isto é, rastreia-se-lhe a viagem completa: do seu porto de origem — sempre o de Montevidéo - ao de destino, registrando-se os portos intermediários, onde atracou para a descarga parcial de mercadorias.

4 AGI, Papeles de Correos, Montevideo, 185. Ofício de 29 de agosto de 1768, de don Agustín de la Roza, governador de Montevideo.

5 Klein, H.: "Structure and profitability...", pág. 441.

6 Os dados para a composição do quadro geral foram extraídos de documentação existente no. AGI, Indiferente General, 2441 a 2446. 
Finalmente, cumpre justificar a minúcia de dados de que tal quadro se acha composto. Nomeia-se a embarcação, caracteriza-se o seu tipo, e as outras indicaçóes ordinarias; em seguida, transcreve-se o calendário da viagem, com data de saída do porto de Montevidéo, nomes dos portos de destino e datas de entrada. Tal levantamento visa ao preenchimento de fichas técnicas das embarcações que, em todos os tempos, realizaram a travessia do Atlântico.?

\section{A análise dos quadros transcritos em apêndice suscita algumas considerações}

O total de embarcações que realizaram a travessia atlântica, no período, foi de 108, predominando o ano de 1787, com 44 barcos.

A fragata e o bergantim foram os tipos de embarcação que maior número de viagens realizaram: 27 cada um, de um total de 108. Há de se considerar, ainda, as 18 travessias operadas por fragatas-correio e as 7 realizadas por paquebotes, navio muito semelhante à fragata e que pelo desenho de perfil longo e pela superestrutura isenta de construções dispensáveis, tornou-se um barco predominantemente veloz, bastante adequado, portanto, para as longas viagens transoceânicas. Se as travessias transatlânticas efetuadas por fragatas-correio e paquebotes forem somadas às realizadas pelas fragatas, emerge este tipo de embarcação como a detentora da supremacia na navegação atlântica.

Transcreve-se a seguir, como dado complementar, quadro contendo os tipos de embarcação empregados na rota platina e o número de viagens realizadas.

\begin{tabular}{lcccc}
$\begin{array}{l}\text { TIPO DE } \\
\text { EMBARCAÇÃO }\end{array}$ & 1787 & 1788 & 1789 & TOTAL \\
\hline fragata & 09 & 10 & 08 & 27 \\
bergantim & 12 & 03 & 12 & 27 \\
fragata-correio & 06 & 06 & 06 & 18 \\
saetia & 09 & 03 & 06 & 18 \\
polaca & 03 & 04 & 03 & 10 \\
paquebote & 05 & 01 & 01 & 07 \\
urca & - & 01 & - & 01 \\
\hline TOTAL & 44 & 28 & 36 & 108 \\
\multicolumn{1}{c}{7 Tarefa coordenada pela Comissão Internacional de História Marítima. }
\end{tabular}


Cabe finalmente, ainda na análise dos diferentes tipos de embarcação empregados no comércio hispano-americano, uma referência à tese esposada por Valentín Vázquez de Prada, em trabalho divulgado no Anuario de Estudios Americanos ${ }^{8}$ Referido Autor faz alusão a navios que denomina de tipo cantábrico e de tipo mediterrâneo; classifica, entre os primeiros, fragatas e bergantins e, entre os segundos, saetias e polacas. Os dados do quadro a seguir transcrito mostram a procedência da afirmação de Vázquez de Prada: houve, efetivamente, uma predominância de fragatas, fragatascorreio e bergantins nos portos de Vigo, La Coruña e Santander. Irrisória foi ai a presença de saetias e polacas, tão numerosas, em contrapartida, em Málaga e Barcelona. A situação de Cádiz, no entanto, foi singular. Por se encontrar, geográfica e historicamente, no ponto de convergência das duas linhas marítimas - a vertente catalã e a vertente biscaína - teve seu porto freqüentado eqüitativamente pelas embarcações de ambos os tipos.

\begin{tabular}{|c|c|c|c|c|c|c|c|c|}
\hline $\begin{array}{l}\text { TIPO DE } \\
\text { EMBARCAÇÃO }\end{array}$ & CÁDIZ & BARCELONA & LA CORUÑA & MÁLAGA & SANTANDER & VIGO & $\begin{array}{l}\text { PALMA DE } \\
\text { MALLORCA }\end{array}$ & TOTAL \\
\hline fragata & 18 & 02 & 02 & 02 & 04 & 02 & - & 30 \\
\hline bergantim & 11 & 17 & 01 & 05 & 04 & 01 & 01 & 40 \\
\hline fragata-correio & - & - & 18 & - & - & - & - & 18 \\
\hline saetia & 10 & 15 & 01 & 06 & - & - & - & 32 \\
\hline polaca & 08 & 09 & - & 02 & - & - & - & 19 \\
\hline paquebote & 04 & 03 & - & 03 & 01 & - & - & 11 \\
\hline urca & 01 & - & - & - & - & - & - & 01 \\
\hline ГOTAL & 52 & 46 & 22 & 18 & 09 & 03 & 01 & 151 \\
\hline
\end{tabular}

Tem sido aceita por procedente a afirmação de que os critérios adotados pela Coroa de Espanha para a habilitação de portos de comércio livre na Península, não consideraram, fundamentalmente, a atuação e a realidade econômica das cidades cabeça de região, eventualmente contidas e reprimidas pelo sistema do exclusivo até então vigente, embora já atenuado por medidas de liberalização da economia comercial, adotadas no decorrer do século. Teria prevalecido sim, naquela iniciativa, uma "doutrina" geográfica. Visava-se, com isto, ao fortalecimento da economia de zonas da

8 Vázquez de Prada, Valentín: "Las rutas comerciales entre España y América”. Anuario de Estudios Americanos, Sevilla, 1968, T. XXV, págs.197-241. 
metrópole, até então consideradas periféricas. ${ }^{9}$ Dai ter a Coroa espanhola pontilhado, com absoluta regularidade, as costas litorâneas de Espanha - a cantábrica, a atlântica e a mediterrânea- de portos habilitados.

$\mathrm{O}$ exame do quadro geral do movimento de embarcações com registro de comércio livre, na vertente platina, permite, ademais das considerações acima expressadas, algumas outras constatações.

Cádiz continuou a desfrutar a condição de grande porto do comércio hispano-americano. Múltiplas razões explicam essa predominância. Entre outras, deve-se destacar: a da existência, em Cádiz, de uma infraestrutura portuária que, desde há séculos, funcionava e buscava seu contínuo aprimoramento; a de natureza histórica, que reconhecia naquela cidade o porto da América; a referente à situação geográfica de Cádiz, ponto de convergência da Espanha mediterrânea e da Espanha cantábrica; a dos interesses de uma poderosa burguesia, solidamente consolidada naquela cidade; finalmente, a da presença de inúmeros e importantes organismos oficiais que, por estarem sediados naquela cidade, promoviam e facilitavam o trato comercial.

Outra constatação refere-se à crescente importância portuária de Barcelona no Mediterrâneo espanhol. Seu crescimento como tal, no transcurso da segunda metade do século XVIII, já foi colocado de manifesto por Pierre Vilar. ${ }^{10}$ Foi essa importância e esse crescimento, respaldados em dados estatísticos trabalhados pelo historiador francês, que permitem amparar a afirmação de Vázquez de Prada de que, por ocasião da publicação do Regulamento de 1778 , a navegação atlântica havia passado às mãos dos catalães. ${ }^{11}$

É possível, ainda, uma terceira constatação. A despeito da política de estímulo da economia espanhola, posta em prática pela Coroa, habilitando portos ao comércio livre, vários destes não chegaram a se transformar em reais e dinâmicos núcleos de tráfico comercial. Alguns destes portos, inclusive, não chegaram a ter sequer uma das 151 atacações verificadas na rota platina do comércio livre, durante os três anos de que trata o presente estudo.

Para ilustrar as constatações supra, transcreve-se, a seguir, quadro em que se fixa o número de atracações, para descarga, de embarcações com

\footnotetext{
9 Ibídem, pág. 228.

10 Vilar, Pierre: La Catalogne, v. 3, pág. 338 e segts. Vázquez de Prada, V.: "Las rutas comerciales...”, pág. 229.

11 Vázquez de Prada, V.: “Las rutas comerciales...”, pág. 230.
} 
registro de comércio livre, em portos habilitados da Espanha, nos anos de 1787 a 1789, da carreira platina.

\begin{tabular}{lcccc} 
PORTO & 1787 & 1788 & 1789 & TOTAL \\
\hline Cádiz & 16 & 15 & 21 & 52 \\
Barcelona & 23 & 09 & 14 & 46 \\
La Coruña & 08 & 07 & 07 & 22 \\
Málaga & 09 & 04 & 05 & 18 \\
Santander & 04 & 03 & 02 & 09 \\
Vigo & 02 & 01 & - & 03 \\
Palma de Mallorca & - & - & 01 & 01 \\
\hline TOTAL & 62 & 39 & 50 & 151
\end{tabular}

\section{Mercadorias, Valores e Tributos}

Variadíssima foi a gama de mercadorias, com destino à Espanha, transportadas pelas embarcações de comércio livre procedentes dos portos platinos.

Embora o couro, a prata e ouro, como adiante se verá, tenham sido responsáveis, em conjunto, por $95 \%$ do valor de todos os gêneros conduzidos e por $98 \%$ dos direitos de entrada recolhidos aos cofres da Coroa e de organismos oficiais da Espanha, a natureza e a quantidade das demais mercadorias arroladas nos registros das embarcações que operaram na rota platina do comércio livre, refletem a intensa e dinâmica atividade de produção e comercialização regional.

A análise do movimento de mercadorias transportadas pelas 108 embarcações que deixaram o porto de Montevidéo no triênio 1787-1789, com registro de comércio livre, conforme dados extraídos de documentação existente no Archivo General de Indias, de Sevilla, ${ }^{12}$ sugere ponderações preliminares.

Deve ser considerado, em primeiro lugar, que as embarcações com registro de comércio livre serviram, prioritariamente, para o transporte de gêneros por conta e risco de particulares. Houve a predominância esmagadora de tais remessas em relação àquelas de interesse, ou por conta e risco, da Coroa ou de organismos oficiais, os Ministérios em particular.

12 AGI, Indiferente General, 2441 a 2446. 
A documentação pesquisada mostra que, além de algumas partidas de prata e ouro, de responsabilidade oficial, e do registro, ainda em prata e ouro, das cajas de soldadas, ${ }^{13}$ apenas em duas embarcações, das 108 que deixaram o porto de Montevidéo no período em estudo, houve carga por conta e risco da Coroa: uma partida de pele e lã de vicunha registrada na fragata-correio "El Águila", de propriedade da Coroa, arribada ao porto de La Coruña no dia 15 de setembro de 1787; uma partida constante de pele e lã de vicunha, tabaco e bálsamo, registrada na urca "S.Amalia", igualmente de propriedade da Coroa, chegada ao porto de Cádiz em 23 de julho de 1788.

Deve-se dar relevo, ainda, como há pouco foi referido, à enorme variedade de gêneros americanos exportados para a Espanha. Os artigos, a seguir relacionados, serão agrupados segundo sua natureza.

\section{Produtos de origem mineral}

Prata; ouro; cobre; estanho; pedras preciosas; cobre granalla; ${ }^{14}$ diamante rosa; $;{ }^{15}$ piedra lipís; ${ }^{16}$ plancha de asta. ${ }^{17}$

\section{Produtos de origem animal}

Couro em cabelo; couro curtido; tarjetas de couro; corachas; ${ }^{18}$ zaleas; ${ }^{19}$ baquetas $;{ }^{20}$ pellones; ${ }^{21}$ solas; sebos; lã de: carneiro, vicunha, guanaco, do Chile; cerdas; pele de: carneiro, tigre, veado, cisne, coelho, vicunha, guanaco, alpaca, pássaros, leão marinho, lobo marinho, zorrillo, ${ }^{22}$ chinchilla, ${ }^{23}$

13 Soldada: soldo, salário, estipêndio ou remuneração pagos à tripulação de um navio.

14 O metal reduzido a grãos miúdos. lapidar.

15 Diamante talhado em facetas, por cima; por baixo, apresenta superfície achatada ou por

16 Pedra-lipes; nome vulgar do vitríolo azul (sulfato de cobre).

17 Lâmina de metal, com haste, à guisa de arma. Hasta. Ferro de passar.

18 Saco de couro para o transporte de tabaco, cacau etc.

19 Couro de ovelha ou de carneiro, curtido de forma a conservar a lã.

20 Couro de novilha curtido.

21 Pelegos.

22 Mamífero da América do Sul, semelhante a uma pequena raposa.

23 Mamífero roedor da América do Sul, mais propriamente dos Andes; sua pele é muito apreciada para agasalhos. 
guia-pies ou guiapies ou guillapies (couros e peles) $;{ }^{24}$ velas de: sebo, espermacete de baleia; plumeiros ou penachos; plumas de avestruz; crina de cavalo; manteiga; queijo; azeite de lobo marinho; gordura de: porco, baleia, lobo marinho; carne salgada; línguas salgadas de vaca; carnazas; ${ }^{25}$ fresadas $;{ }^{26}$ hastes de touro; pesuñas de novillo; ${ }^{27}$ coyundas de toro ${ }^{28}$ intestinos. ${ }^{29}$

\section{Produtos de origem vegetal}

Tabaco; trigo; farinha; algodão com sementes; cacau Guaiaquil; cacau de Mojos; chocolate em pasta; cascarilla; ${ }^{30}$ orejones de durazno; ${ }^{31}$ caña; ${ }^{32}$ hierva; ${ }^{33}$ erva do Paraguai; pastilhas de cheiro; quina; vinho de Tubela; vinho de Tucumán; contrahierba; ${ }^{34}$ erva de culén; ${ }^{35}$ higuerilla; ${ }^{36}$ canchalagua ${ }^{37}$ calaguala ${ }^{38}$ bejuquillo; ${ }^{39}$ palo bobo; ${ }^{40}$ palo santo; ${ }^{41}$ madeira de Urunday; ${ }^{42}$ sassafrás; caoba; ${ }^{43}$ bálsamo; cedro.

24 Trata-se de expressão controvertida. Tanto pode significar ou tapete de couro ou pele; ou estribo do mesmo material, no qual o cavaleiro firma o pé; ou, ainda, segundo acepção catalã, couro ou pele do guilla (pequena raposa).

25 Sebo.

26 Espécie de alimento, com ingredientes de origem animal.

27 Dedos, cobertos por unhas, de animais de patas fendidas.

28 Correia forte e larga, com que se atam os bois à canga.

29 Tripas.

30 Casca de uma árvore da América, da família das Euforbiáceas, amarga, aromática e medicinal. Espécie de quina branca e fina. Casca de cacau tostada, de cuja infusão se faz bebida a ser tomada quente.

31 Pedaços de pêssego, secos ao sol.

32 Nome genérico, extensivo a várias plantas gramíneas. Parte da bota que cobre a perna.

33 Referência provável à erva-mate.

34 Planta da América Meridional, usada em medicina como contra-veneno.

35 Leguminosa natural do Chile. A bebida resultante da Infusão de suas folhas é tomada para as enfermidades do estômago. Rícino.

36 Figueira, árvore da família das moráceas. Figueira-do-inferno, planta tóxica e medicinal.

37 Planta americana, da família das Gencianáceas, usada em medicina.

38 Planta medicinal, originária do Perú.

39 Ipecacuanha. Planta medicinal da família das Rubiáceas, própria da América Meridional, cuja raiz é muito usada como emética, tônica e purgante.

40 Trata-se, provavelmente, de vegetal empregado em farmácia, para fins medicinais.

41 Madeira do guaiacó, árvore medicinal da América Tropical, da família das Zigofiláceas.

42 Árvore terebintácea, da Argentina, de madeira cor vermelho-escuro, empregada na construção de navios e móveis.

43 Árvore da América, da família das Meliáceas. Sua madeira era empregada, sobretudo, na construção de móveis.

44 Tecido para vestuário comprido, feito regularmente de peles. 


\section{Outros produtos}

Mesas de madeira do Paraguai; roupas; livros; luvas de pele; paños de pellón; $;{ }^{44}$ alfombras de lana; $;{ }^{45}$ grana de Santiago $;{ }^{46}$ chaxaes. ${ }^{47}$

Cabe registrar, ademais, que na carga transportada pelo bergantim "S.Jayme", de propriedade particular, com arribadas em Cádiz e Barcelona, respectivamente nos dias 7 de janeiro e 17 de março de 1788, constava, com valor estipulado, 1 esclavo negro. Tal situação ocorreria, igualmente, com a fragata de guerra "N. Señora de la Ó", de propriedade da Coroa, que no dia 20 de junho de 1789 atracou em Cádiz, ao registrar, junto à mercadoria transportada, 1 esclavo y 2 negros, também com valor fixado. Pelo inusitado, vale referir que a fragata-correio "La Cantabria", da Coroa, chegada ao porto de La Coruña em 16 de junho de 1788, transportava para a Espanha 7 caxones con huesos de un animal extraordinario.

Finalmente, cumpre destacar as colossais transferências de metais preciosos, por meio do registro como carga de partidas de ouro e prata. Estes metais eram transportados ou em pasta, isto é, fundidos mas não trabalhados, ou já lavrados ou, ainda, cunhados ou amoedados.

\section{Movimento Geral de Mercadorias}

\section{A Prata, o Ouro e o Couro}

$\mathrm{O}$ resultado da pesquisa referente ao movimento de mercadorias permite constatações concretas a respeito do valor dos gêneros americanos, da sua importância econômica no conjunto dos produtos objeto de importação, e dos direitos recolhidos, à guisa de tributação, pela Coroa espanhola e demais organismos oficiais.

O valor total das mercadorias transportadas pelas embarcações com registro de comércio livre, dos portos platinos para os habilitados de Espanha, no triênio 1787-1789, alcançou a expressiva soma de 325.189.910 reales de vellón(rv), recolhendo o total de $12.422 .605 \mathrm{rv}$ de direitos de entrada, incidentes sobre os vários gêneros, nos termos do

45 Tapetes de lã, coloridos e com desenhos.

46 Semente miúda de vários vegetais. Cochinilla. Quermes. Excrescência vermelha formada por inseto sobre folhas de um tipo de ca.rvalho. Tecido fino.

47 Significa, eventualmente, um tipo de chapéu. 
Regulamento de 1778. A prata, o ouro e o couro desfrutaram de indiscutível relevância, nesse contexto.

A soma dos valores dos três produtos, no triênio, totalizou 310.572 .729 rv, que correspondem a $95 \%$ do valor total das mercadorias registradas e transportadas.

A tributação incidente sobre os três produtos, consubstanciada nos direitos de entrada, alcançou níveis ainda maiores do que o valor em relação ao total. Os três gêneros recolheram, no triênio, a soma de 12.148.527 rv de direitos, correspondentes a $98 \%$ do total de direitos pagos por todos os gêneros.

Tais dados permitem constatar que, à exceção dos três produtos "nobres" acima referidos, coube aos demais gêneros, exportados não poucas vezes em quantidades significativas, as modestas cifras de 14.617.181 rv de valor e $274.078 \mathrm{rv}$ de direitos de entrada. Tais dados ensejam a reflexão de que a dimensão econômica do implantado sistema do comércio livre se justificaria, como teria se justificado, pelo trato exclusivo da prata, do ouro e do couro.

A prata foi o gênero de maior relevância e predomínio nos registros das embarcações dedicadas ao comércio livre. No triênio 1787/1789 foi responsável por 186.940 .272 rv de valor, que correspondem a 57\% do total, e por 8.113.294 rv de direitos de entrada, equivalentes a $65 \%$ do global. Esteve presente nos registros de 43 das 44 embarcações que deixaram o porto de Montevidéo no ano de 1787; nos das 28 de 1788; nos de 33 das 36 de 1789. Em 1787 alcançou o valor de 60.167.101 rv, dos quais 51.763.151 por conta de particulares. Em 1788 tal valor ascendeu a $62.925 .928 \mathrm{rv}$, dos quais 56.145.819 da responsabilidade de particulares. Maior ainda foi o valor em 1789, que totalizou 63.847.243 rv, dos quais 51.279.647 de particulares. Recolheu nesses três anos, por direitos de entrada, respectivamente, as quantias de $2.612 .963,2.914 .835$ e $2.585 .496 \mathrm{rv}$.

O couro ocupou o $2 .{ }^{\circ}$ lugar, em termos de importância, entre os gêneros americanos exportados pelos portos platinos. No triênio 1787-1789 foi responsável por 66.413.487 rv de valor, que correspondem a $20 \%$ do total, e por $3.187 .138 \mathrm{rv}$ de direitos de entrada, equivalentes a $26 \%$ do global. Esteve presente nos registros de 41 das 44 embarcações que deixaram o porto de Montevidéo no ano de 1787; nos das 28 de 1788; nos de 33 das 36 de 1789. Em 1787 alcançou o valor de 19.555.770 rv; em 1788, 23.988.659; em 1789, 22.869 .058 rv. Recolheu nesses três anos, por direitos de entrada, respectivamente, as quantias de 939.353, $1.200 .943 \mathrm{e}$ 
1.146.842 rv. No triênio foram exportadas 1.189 .579 peças de couro em cabelo, com o peso de 27.594.345 libras, correspondendo 364.998 peças com 7.703.954 libras de peso ao ano de 1787; 406.631 peças com 10.043.492 libras de peso ao de $1788 ; 417.950$ peças com 9.846 .899 libras de peso ao ano de 1789. Tais cifras demonstram, de forma eloqüente, a importância cada vez maior que Buenos Aires e, por extensão, toda a região platina assumiam como o principal centro produtor e exportador de couros na América Ibérica colonial. Jaime Vicens Vives, ao denominar Buenos Aires, com absoluta propriedade, "a metrópole do couro", ${ }^{48}$ fixou a cifra de 150.000 peças de couro exportadas anualmente pelos portos platinos para a Espanha. Tal número refere-se, grosso modo, ao terceiro quartel do século XVIII. Verifica-se, assim, que a cifra estabelecida por Vicens Vives está, de longe, superada pela exportação anual dessa pele, no triênio a que se refere o presente estudo. Esta realidade reflete, de um lado, o desenvolvimento das atividades de produção e comercialização do couro, na região em análise; mostra, por outro lado, o estímulo à exportação, ensejado pelo maior número de embarcações nos portos platino, como decorrência do instituto do comércio livre. Tais afirmações estão corroboradas, de resto, pelos resultados a que tivemos a oportunidade de chegar, quando do estudo da instituição do Correio Marítimo entre Espanha e suas colônias americanas, na segunda metade do século XVIII ${ }^{49}$ Naquela oportunidade verificamos que, no período de 1768 a 1778, 55 fragatas-correio, empregadas no sistema, foram responsáveis pelo transporte de 425.250 peças de couro em cabelo para a Espanha, embarcadas no porto de Montevidéo. Significativa demonstração do que acima se afirmou, é constatar o fato de que 102 embarcações, com registro de comércio livre, transportaram do mesmo porto de Montevidéo para os habilitados de Espanha, no triênio 1787-1789, 1.189 .579 peças de couro em cabelo.

O ouro ocupou o terceiro lugar na pauta de exportação dos produtos americanos, na vertente platina. No triênio 1787-1789, o ouro foi responsável por $57.218 .970 \mathrm{rv}$ de valor, que correspondem a $18 \%$ do total, e por $848.095 \mathrm{rv}$ de direitos de entrada, equivalentes a 7\% do global. Esteve presente no registro de 19 das 44 embarcações que deixaram o porto de Montevidéo no ano de 1787; no de 18 das 28 de 1788; no de 14 das 36 de

48 Vicens Vives, Jaime: Historia Economica de España. Barcelona, 1967, pág. 496.

49 Bellotto, Manoel Lelo: Correio Marítimo Hispano-Americano. A Carreira de Buenos Aires (1767-1779). Assis, 1971, pág. 245. 
1789. Em 1787 alcançou o valor de $18.499 .815 \mathrm{rv}$, dos quais 18.339 .815 por conta de particulares. Em 1788 tal valor ascendeu a $19.452 .524 \mathrm{rv}$, dos quais 18.852.793 de responsabilidade de particulares. Em 1789 o valor totalizou 19.266.631 rv, dos quais 19.226.631 por conta de particulares. Recolheu nesses três anos, por direitos de entrada, respectivamente, as quantias de $276.025,283.525$ e $288.545 \mathrm{rv}$.

Demais produtos que ocuparam posição de destaque na pauta de exportação, pela frequiência com que apareceram nos róis de embarque e pelos valores consignados, foram as peles, de um modo geral, o sebo e as lãs, a de carneiro em particular. Em relação a este último gênero, cumpre ressaltar a preocupação das autoridades metropolitanas, sediadas no Prata, em criar condições para a colocação, na Espanha, de um produto colonial que pudesse, ao menos, ombrear-se à importância de que desfrutava, na pauta das exportações, o couro. A lã platina era abundante, de baixo custo e excelente qualidade, de amplo consumo no mercado europeu. Nesse sentido, expressiva foi a correspondência mantida ao início do último quartel do século XVIII entre o Administrador dos Correios de Buenos Aires e seus superiores na Metrópole, oportunidade em que foram sugeridas medidas de estímulo à produção e comercialização da lã. ${ }^{50}$

Cumpre afirmar, finalmente, que no triênio 1787-1789, o ano de 1788 foi o mais favorável ao movimento de mercadorias, aquele em que foram alcançados os maiores índices de valores transportados e de direitos de entrada, superando ampliamente os anos de 1789, ao qual coube o segundo lugar, e o de 1787, o de mais fraca realização. No ano de 1788 foram transportadas mercadorias no valor de $115.145 .936 \mathrm{rv}$, que correspondem a $35,4 \%$ do valor total do triênio, e arrecadados $4.433 .813 \mathrm{rv}$ de direitos de entrada, que equivalem a $35,7 \%$ do total dos tributos amealhados nos anos de 1787 a 1789 pela Coroa de Espanha.

50 AGI, Indiferente General, 484. Ofício de 23 de dezembro de 1775 aos diretores gerais da Renda dos Correios.

Tomo LIII, 1, 1996 


\section{Apêndice}

ANO 1787

Movimento DE EMBARCAÇÕES

\begin{tabular}{|c|c|c|c|c|c|c|c|c|}
\hline \multicolumn{2}{|c|}{$N .^{o}$} & \multicolumn{2}{|c|}{ Embarcação } & \multicolumn{5}{|c|}{ Calendário da Viagem } \\
\hline & Nome & Tipo & Capitão & Propriedade & $\begin{array}{l}\text { Saída de } \\
\text { Montevideo }\end{array}$ & Entrada & Entrada & Entrada \\
\hline 1 & N.S. de Gracia & bergantim & Antonio Tutzó & mesmo & 20.01 .87 & $\begin{array}{l}\text { Barcelona } \\
09.07 .87\end{array}$ & & \\
\hline 2 & N.S. del Carmen & paquebote & Luiz Mestre & mesmo & 20.01 .87 & $\begin{array}{l}\text { Barcelona } \\
12.07 .87\end{array}$ & & \\
\hline 3 & El Infante D. Fernando & fragata & Pedro Posadas & mesmo & 03.02 .87 & $\begin{array}{l}\text { Coruña } \\
04.05 .87\end{array}$ & & \\
\hline 4 & La Princesa & $\begin{array}{l}\text { fragata- } \\
\text { correio }\end{array}$ & Jacinto de Vargas & $\begin{array}{l}\text { Coroa } \\
\text { Machuca }\end{array}$ & 13.02 .87 & Coruña & 30.04 .87 & \\
\hline 5 & $\begin{array}{l}\text { N.S. del Buen Suceso } \\
\text { y S. Francisco de Paula }\end{array}$ & fragata & Gil Vochy & mesmo & 23.02 .87 & $\begin{array}{l}\text { Cádiz } \\
18.07 .87\end{array}$ & & \\
\hline 6 & El Valeroso Alejandro & fragata & Manuel de Algorri & mesmo & 01.03 .87 & $\begin{array}{l}\text { Cádiz } \\
05.07 .87\end{array}$ & & \\
\hline 7 & $\begin{array}{l}\text { S. Joaquim } \\
\text { y S. Antonio }\end{array}$ & polaca & Joseph Mascaró & mesmo & 20.03 .87 & $\begin{array}{l}\text { Málaga } \\
28.06 .87\end{array}$ & $\begin{array}{l}\text { Barcelona } \\
25.07 .87\end{array}$ & \\
\hline 8 & $\begin{array}{l}\text { El Dulce Nombre de } \\
\text { María Y S. Cayetano }\end{array}$ & bergantim & Pablo Jover & mesmo & 23.03 .87 & $\begin{array}{l}\text { Cádiz } \\
06.07 .87\end{array}$ & & \\
\hline 9 & N.S. del Socorro & bergantim & Thomas Rives & mesmo & 12.04 .87 & $\begin{array}{l}\text { Santander } \\
11.07 .87\end{array}$ & & \\
\hline 10 & S. Jayme Y Animas & bergantim & Juan Pablo Bru & mesmo & 25.04 .87 & $\begin{array}{l}\text { Cádiz } \\
29.08 .87\end{array}$ & $\begin{array}{l}\text { Barcelona } \\
28.09 .87\end{array}$ & \\
\hline 11 & La Cantabria & $\begin{array}{l}\text { fragata- } \\
\text { correio }\end{array}$ & Antonio & $\begin{array}{l}\text { Coroa } \\
\text { Albuerne }\end{array}$ & 30.04 .87 & Coruña & 13.07 .87 & \\
\hline 12 & S. Antonio de Pádua & fragata & Antonio Gulibart & mesmo & 05.05 .87 & $\begin{array}{l}\text { Málaga } \\
21.08 .87\end{array}$ & $\begin{array}{l}\text { Barcelona } \\
18.09 .87\end{array}$ & \\
\hline 13 & S. Francisco de Paula & saetia & Francisco Soler & mesmo & 08.05 .87 & $\begin{array}{l}\text { Málaga } \\
31.07 .87\end{array}$ & $\begin{array}{l}\text { Barcelona } \\
09.09 .87\end{array}$ & \\
\hline 14 & S. Antonio de Pádua & paquebote & $\begin{array}{l}\text { Bartholomé } \\
\text { Roitag }\end{array}$ & mesmo & 19.05 .87 & $\begin{array}{l}\text { Cádiz } \\
16.09 .87\end{array}$ & $\begin{array}{l}\text { Málaga } \\
24.10 .87\end{array}$ & $\begin{array}{l}\text { Barcelona } \\
13.11 .87\end{array}$ \\
\hline 15 & N.S. de la Concepción & fragata & Juan Antonio & mesmo & $?$ & $\begin{array}{l}\text { Vigo } \\
15.09 .87\end{array}$ & & \\
\hline 16 & S. Antonio Y S. Pablo & paquebote & Pablo Aymerich & mesmo & 05.06 .87 & $\begin{array}{l}\text { Cádiz } \\
14.09 .87\end{array}$ & $\begin{array}{l}\text { Barcelona } \\
21.12 .87\end{array}$ & \\
\hline 17 & La Venzedora & fragata & $\begin{array}{l}\text { Juan Antonio } \\
\text { Fernández } \\
\text { del Villar }\end{array}$ & $\begin{array}{l}\text { Buenaventura } \\
\text { Marcó del Pont }\end{array}$ & 08.06 .87 & $\begin{array}{l}\text { Vigo } \\
18.01 .88\end{array}$ & & \\
\hline
\end{tabular}




\begin{tabular}{|c|c|c|c|c|c|c|c|c|}
\hline & Nome & Tipo & Capitão & Propriedade & $\begin{array}{l}\text { Saída de } \\
\text { Montevideo }\end{array}$ & ${ }_{o}$ Entrada & Entrada & Entrada \\
\hline 18 & S. Antonio Abad & paquebote & Gabriel Puig & mesmo & 11.06 .87 & $\begin{array}{l}\text { Málaga } \\
17.09 .87\end{array}$ & & \\
\hline 19 & $\begin{array}{l}\text { La Concepción } \\
\text { Y S. Joseph }\end{array}$ & saetia & $\begin{array}{l}\text { Antonio Luiz } \\
\text { Martinez }(*)\end{array}$ & mesmo & 15.06 .87 & $\begin{array}{l}\text { Málaga } \\
22.09 .87\end{array}$ & $\begin{array}{l}\text { Barcelona } \\
01.10 .87\end{array}$ & \\
\hline 20 & El Águila & $\begin{array}{l}\text { fragata- } \\
\text { correio }\end{array}$ & Juan Fuso & Coroa & 23.06 .87 & $\begin{array}{l}\text { Coruña } \\
15.09 .87\end{array}$ & & \\
\hline 21 & El Tártaro & fragata & $\begin{array}{l}\text { Francisco Antonio } \\
\text { de Belausteguí }\end{array}$ & mesmo & 27.07 .87 & $\begin{array}{l}\text { Cádiz } \\
24.10 .87\end{array}$ & & \\
\hline 22 & N. S. del Carmen & polaca & Estevan Guisart & mesmo & 30.07 .87 & $\begin{array}{l}\text { Cádiz } \\
25.10 .87\end{array}$ & $\begin{array}{l}\text { Barcelona } \\
12.11 .87\end{array}$ & \\
\hline 23 & La Virgen del Carmen & saetia & Ramón Batlla & mesmo & 02.08 .87 & $\begin{array}{l}\text { Cádiz } \\
20.10 .87\end{array}$ & $\begin{array}{l}\text { Barcelona } \\
19.12 .87\end{array}$ & \\
\hline 24 & N. S. de la Merced & bergantim & Jayme Moré & mesmo & 03.08 .87 & $\begin{array}{l}\text { Santander } \\
26.10 .87\end{array}$ & & \\
\hline 25 & S. Christoval & saetia & Christoval Cerda & mesmo & 06.08 .87 & $\begin{array}{l}\text { Cádiz } \\
19.12 .87\end{array}$ & $\begin{array}{l}\text { Barcelona } \\
19.12 .87\end{array}$ & \\
\hline 26 & $\begin{array}{l}\text { S. Buenaventura (alias) } \\
\text { El Conde de Cifuentes }\end{array}$ & fragata & $\begin{array}{l}\text { Antonio Durán } \\
\text { y Prats }\end{array}$ & mesmo & 06.08 .87 & $\begin{array}{l}\text { Cádiz } \\
02.11 .87\end{array}$ & & \\
\hline 27 & $\begin{array}{l}\text { La Purificación } \\
\text { de N. Señora }\end{array}$ & polaca & $\begin{array}{l}\text { Buenaventura } \\
\text { Masoni }\end{array}$ & mesmo & 09.08 .87 & $\begin{array}{l}\text { Cádiz } \\
20.12 .87\end{array}$ & $\begin{array}{l}\text { Barcelona } \\
? .03 .88\end{array}$ & \\
\hline 28 & S. Francisco de Asis & saetia & Jayme Roitg & mesmo & 16.08 .87 & $\begin{array}{l}\text { Coruña } \\
30.10 .87\end{array}$ & & \\
\hline 29 & N. S. del Carmen & paquebote & Josef Elers & mesmo & 22.08 .87 & $\begin{array}{l}\text { Cádiz } \\
04.01 .88\end{array}$ & & \\
\hline 30 & La Infanta & $\begin{array}{l}\text { fragata- } \\
\text { correio }\end{array}$ & Juan Antonio & $\begin{array}{l}\text { Coroa } \\
\text { Gonzales }\end{array}$ & 25.08 .87 & Coruña & 26.10 .87 & \\
\hline 31 & La Resolución & bergantim & Josef de la Calleja & mesmo & 27.08 .87 & $\begin{array}{l}\text { Barcelona } \\
19.12 .87\end{array}$ & & \\
\hline 32 & S. Quirze y S. Julita & saetia & Juan Bofill & mesmo & 04.09 .87 & Barcelona & 18.02 .88 & \\
\hline 33 & S. Juan Bauptista & saetia & $\begin{array}{l}\text { Feliciano } \\
\text { Carnesoltas }\end{array}$ & mesmo & 07.09 .87 & Cádiz & $\begin{array}{l}\text { Barcelona } \\
12.02 .88\end{array}$ & 31.03 .88 \\
\hline 34 & Jesus María y Joseph & saetia & Jayme Lacort & mesmo & 11.09 .87 & Málaga ? & $\begin{array}{l}\text { Barcelona } \\
13.02 .88\end{array}$ & \\
\hline 35 & N. S. de los Dolores & bergantim & Francisco Oliver & mesmo & 12.09 .87 & $\begin{array}{l}\text { Santander } \\
11.12 .87\end{array}$ & & \\
\hline 36 & $\begin{array}{l}\text { La Santísima Trinidad } \\
\text { y N. S. de Monserrat }\end{array}$ & bergantim & Monserrat Sagarra & mesmo & 20.09 .87 & $\begin{array}{l}\text { Cádiz } \\
07.01 .88\end{array}$ & $\begin{array}{l}\text { Barcelona } \\
17.03 .88\end{array}$ & \\
\hline 37 & La Esperanza & bergantim & Juan Sintes & mesmo & 06.10 .87 & $\begin{array}{l}\text { Málaga } \\
10.02 .88\end{array}$ & $\begin{array}{l}\text { Barcelona } \\
10.03 .88\end{array}$ & \\
\hline 38 & El Patagón & $\begin{array}{l}\text { fragata- } \\
\text { correio }\end{array}$ & Ignácio Perez & Coroa & 09.10 .87 & Coruña & 01.01 .88 & \\
\hline 39 & S. Jayme & bergantim & Jaime Gual & mesmo & 19.10 .87 & $\begin{array}{l}\text { Cádiz } \\
07.01 .88\end{array}$ & $\begin{array}{l}\text { Barcelona } \\
17.03 .88\end{array}$ & \\
\hline
\end{tabular}




\begin{tabular}{|c|c|c|c|c|c|c|c|c|}
\hline & Nome & Tipo & Capitão & Propriedade & $\begin{array}{l}\text { Saída de } \\
\text { Montevideo }\end{array}$ & Entrada & Entrada & Entrada \\
\hline 40 & N. S. de la Merced & saetia & Josef Fabregas & mesmo & 06.11 .87 & $\begin{array}{l}\text { Barcelona } \\
06.03 .88\end{array}$ & & \\
\hline 42 & N. S. de la Merced & fragata & Geronimo Soliveras & & mesmo & 13.11 .87 & $\begin{array}{l}\text { Santander } \\
02.06 .88\end{array}$ & \\
\hline 43 & La Diligencia & $\begin{array}{l}\text { fragata } \\
\text { correio }\end{array}$ & $\begin{array}{l}\text { Manuel } \\
\text { Fernandez Trelles }\end{array}$ & Coroa & 08.12 .87 & $\begin{array}{l}\text { Coruña } \\
25.02 .88\end{array}$ & & \\
\hline
\end{tabular}

(*) N. ${ }^{\circ}$ 19. O Capitão no trecho Málaga - Barcelona foi Antonio Parera

ANO: 1788

$N^{o}$$$
\longrightarrow
$$

Nom

Nome

Embarcação

MOVIMENTO DE EMBARCAÇõES

Tipo Capitão

Propriedade
Juan Puig de Padua

02 La Princesa

03 El Terrible

04 La Condesa de Benavente

05 S. Pedro y S. Pablo

06

06 El Santo de la Victoria

07 El Rey

08 S. Amália

09 La Perla de la Habana fragata

10 La Cantabria

fragata-

correio

correio

Thenorio

bergantim Jayme Morro

fragata

de Aguirre

Francisco

Fernandez

fragata- Francisco

correio de Llano

urca

Juan Antonio

Amiont

Juan Angel de Urgarte

de Musquiz

Francisco Abello Coroa

Felipe Diaz mesmo

Josef Antonio

Luis Antonio

Montevideo

03.01.88 Barcelona

15.01.88 Coruña

04.04 .88

24.01.88 Cádiz

20.06.88

07.02.88 Cádiz Barcelona

12.08.88 20.10.88

01.03.88 Santander

14.07.88

Buenaventura 15.03.88 Vigo

Marcó del Pont

Coroa

09.06 .88

16.03.88 Coruña

16.06 .88

Coroa

21.03.88 Cádiz

23.07.88

Francisco

de Sierra

09.05 .88

Coruña

01.12 .88

Coroa

12.05.88 Coruña

16.07.88 


\begin{tabular}{|c|c|c|c|c|c|c|c|c|}
\hline & Nome & Tipo & Capitão & Propriedade & $\begin{array}{l}\text { Saída de } \\
\text { Montevideo }\end{array}$ & Entrada & Entrada & Entrada \\
\hline 11 & N. S. las Mercedes & paquebote & Francisco Jova & mesmo & 16.05 .88 & $\begin{array}{l}\text { Cádiz } \\
29.09 .88\end{array}$ & $\begin{array}{l}\text { Málaga } \\
30.11 .88\end{array}$ & \\
\hline 12 & La Esperanza & fragata & Juan de Ballivián & $\begin{array}{l}\text { Manuel } \\
\text { de Vergareche }\end{array}$ & 21.05 .88 & $\begin{array}{l}\text { Santander } \\
09.09 .88\end{array}$ & & \\
\hline 13 & N.S. del Buen Viage & fragata & Ramon Plá & mesmo & 29.05 .88 & $\begin{array}{l}\text { Cádiz } \\
16.09 .88\end{array}$ & & \\
\hline 14 & N.S. del Buen Viage & polaca & Jayme Roger & mesmo & 29.05 .88 & $\begin{array}{l}\text { Cádiz } \\
14.09 .88\end{array}$ & $\begin{array}{l}\text { Barcelona } \\
21.11 .88\end{array}$ & \\
\hline 15 & N.S. del Viñet & saetia & Sebastián Coll & mesmo & 03.06 .88 & $\begin{array}{l}\text { Cádiz } \\
21.09 .88\end{array}$ & $\begin{array}{l}\text { Málaga } \\
24.12 .88\end{array}$ & $\begin{array}{l}\text { Barcelona } \\
06.12 .88\end{array}$ \\
\hline 16 & El Peregrino & fragata & $\begin{array}{l}\text { Francisco Ignácio } \\
\text { Galarraga }\end{array}$ & $\begin{array}{l}\text { Inglesa, } \\
\text { fretada pela } \\
\text { Cia. de Filipinas }\end{array}$ & 02.07 .88 & $\begin{array}{l}\text { Cádiz } \\
23.09 .88\end{array}$ & & \\
\hline 17 & S. Francisco de Paula & polaca & Cristobal Carsi & mesmo & 03.07.88 & $\begin{array}{l}\text { Cádiz } \\
07.10 .88\end{array}$ & & $\begin{array}{l}\text { Barcelona } \\
09.12 .88\end{array}$ \\
\hline 18 & S. Antonio de Pádua & polaca & Antonio Carsi & mesmo & 07.07 .88 & $\begin{array}{l}\text { Cádiz } \\
07.10 .88\end{array}$ & & $\begin{array}{l}\text { Barcelona } \\
06.12 .88\end{array}$ \\
\hline 19 & El Águila & fragata-corr & & Manuel de Abona & & Coroa & $\begin{array}{l}29.07 .88 \\
11.10 .88\end{array}$ & Coruña \\
\hline 20 & La Purísima Concepción & & polaca & Ramon Ruiz & mesmo & 06.08 .88 & $\begin{array}{l}\text { Málaga } \\
11.12 .88\end{array}$ & \\
\hline 21 & N.S. del Rosario & fragata & Salvador Vidal & mesmo & 08.08 .88 & $\begin{array}{l}\text { Málaga } \\
11.12 .88\end{array}$ & $\begin{array}{l}\text { Cádiz } \\
08.01 .89\end{array}$ & $\begin{array}{l}\text { Barcelona } \\
26.02 .89\end{array}$ \\
\hline 22 & La Peregrina & fragata & Charles Sloper & $\begin{array}{l}\text { Inglesa da } \\
\text { Cia. de Bristol. } \\
\text { Trecho Mont. - } \\
\text { Santander da } \\
\text { Cia. de Filipinas }\end{array}$ & 13.08 .88 & $\begin{array}{l}\text { Santander } \\
11.11 .88\end{array}$ & & \\
\hline 23 & La Menorca & fragata & $\begin{array}{l}\text { Josef de } \\
\text { Bustamante } \\
\text { y Gayon }\end{array}$ & mesmo & 16.08 .88 & $\begin{array}{l}\text { Cádiz } \\
05.12 .88\end{array}$ & & \\
\hline 24 & La Infanta & $\begin{array}{l}\text { fragata- } \\
\text { correio }\end{array}$ & $\begin{array}{l}\text { Manuel } \\
\text { Fernández Trelles }\end{array}$ & Coroa & 08.10 .88 & $\begin{array}{l}\text { Coruña } \\
16.12 .88\end{array}$ & & \\
\hline 25 & S. Cayetano & saetia & Miguel Mauri & mesmo & 29.11 .88 & $\begin{array}{l}\text { Cádiz } \\
26.02 .89\end{array}$ & $\begin{array}{l}\text { Barcelona } \\
20.03 .89\end{array}$ & \\
\hline 26 & N.S. del Carmen & bergantim & Jacinto Lloret & mesmo & 25.11 .88 & $\begin{array}{l}\text { Cádiz } \\
09.04 .89\end{array}$ & $\begin{array}{l}\text { Barcelona } \\
05.06 .89\end{array}$ & \\
\hline 27 & La Princesa & $\begin{array}{l}\text { fragata- } \\
\text { correio }\end{array}$ & $\begin{array}{l}\text { Jacinto Vargas } \\
\text { Machuca }\end{array}$ & Coroa & 28.11 .88 & $\begin{array}{l}\text { Coruña } \\
09.02 .89\end{array}$ & & \\
\hline 28 & $\begin{array}{l}\text { N.S. del Buensuceso } \\
\text { y S. Francisco } \\
\text { de Paula }\end{array}$ & fragata & $\begin{array}{l}\text { Bartolome de } \\
\text { Soria Santa Cruz }\end{array}$ & $\begin{array}{l}\text { Luiz Francisco } \\
\text { Navarro }\end{array}$ & 23.12 .88 & $\begin{array}{l}\text { Cádiz } \\
02.05 .89\end{array}$ & & \\
\hline
\end{tabular}


ANO: 1789

Movimento DE EMBARCAÇÕES

$N^{o}$

Embarcação

Calendário da Viagem

\begin{tabular}{|c|c|c|c|c|c|c|c|}
\hline & Nome & Tipo & Capitão & Propriedade & $\begin{array}{l}\text { Saída de } \\
\text { Montevideo }\end{array}$ & Entrada & Entrada \\
\hline 01 & El Patriarca S. Josef & paquebote & Manuel de Garay & $\begin{array}{l}\text { Manuel de } \\
\text { Vergareche }\end{array}$ & 05.01 .89 & $\begin{array}{l}\text { Santander } \\
19.04 .89\end{array}$ & \\
\hline 02 & S. Antonio y S. Pablo & polaca & Pablo Aymerich & mesmo & 09.01 .89 & $\begin{array}{l}\text { Cádiz } \\
09.04 .89\end{array}$ & $\begin{array}{l}\text { Barcelona } \\
28.05 .89\end{array}$ \\
\hline 03 & N. S. del Carmen & fragata & $\begin{array}{l}\text { Domingo } \\
\text { Urtetegui }\end{array}$ & Josef Caveases & 24.01 .89 & $\begin{array}{l}\text { Cádiz } \\
21.05 .89\end{array}$ & \\
\hline 04 & El Rey & $\begin{array}{l}\text { fragata- } \\
\text { correio }\end{array}$ & $\begin{array}{l}\text { Francisco } \\
\text { de Llano }\end{array}$ & Coroa & 02.02 .89 & $\begin{array}{l}\text { Coruña } \\
09.05 .89\end{array}$ & \\
\hline 05 & N.S. del Rosario & bergantim & $\begin{array}{l}\text { Francisco } \\
\text { Buznego }\end{array}$ & Martin Bunéo & 21.02 .89 & $\begin{array}{l}\text { Cádiz } \\
25.06 .89\end{array}$ & $\begin{array}{l}\text { Palma } \\
\text { de Mallorca } \\
05.09 .89\end{array}$ \\
\hline 06 & N.S. de las Mercedes & fragata & $\begin{array}{l}\text { Antonio Josef } \\
\text { del Corro }\end{array}$ & mesmo & 09.03 .89 & $\begin{array}{l}\text { Cádiz } \\
26.07 .89\end{array}$ & \\
\hline 07 & N.S. del Rosario & saetia & Miguel Granell & mesmo & 14.03 .89 & $\begin{array}{l}\text { Cádiz } \\
13.07 .89\end{array}$ & $\begin{array}{l}\text { Barcelona } \\
31.08 .89\end{array}$ \\
\hline 08 & La Corona & bergantim & Lucas de Begoña & $\begin{array}{l}\text { Real Cia } \\
\text { S. Fernando } \\
\text { de Sevilla }\end{array}$ & 20.03 .89 & $\begin{array}{l}\text { Cádiz } \\
19.07 .89\end{array}$ & \\
\hline 09 & El Pizarro & $\begin{array}{l}\text { fragata- } \\
\text { correio }\end{array}$ & Josef Suarez & $\begin{array}{l}\text { Coroa } \\
\text { Quiros }\end{array}$ & 25.03 .89 & Coruña & 17.06 .89 \\
\hline 10 & N.S. de la Ó & $\begin{array}{l}\text { fragata } \\
\text { de guerra }\end{array}$ & $\begin{array}{l}\text { Miguel } \\
\text { Fernandes } \\
\text { de Azevedo }\end{array}$ & Coroa & 28.03 .89 & $\begin{array}{l}\text { Cádiz } \\
20.06 .89\end{array}$ & \\
\hline 11 & $\begin{array}{l}\text { N.S. de la Misericordia } \\
\text { y S. Bárbara }\end{array}$ & polaca & Salvador Andrew & mesmo & 04.04 .89 & $\begin{array}{l}\text { Cádiz } \\
16.07 .89\end{array}$ & $\begin{array}{l}\text { Barcelona } \\
24.08 .89\end{array}$ \\
\hline 12 & S. Josef y Animas & bergantim & Josef Soler & mesmo & 18.04 .89 & $\begin{array}{l}\text { Cádiz } \\
11.08 .89\end{array}$ & $\begin{array}{l}\text { Barcelona } \\
23.09 .89\end{array}$ \\
\hline 13 & $\begin{array}{l}\text { La Purísima } \\
\text { Concepción } \\
\text { y S. Josef }\end{array}$ & saetia & Antonio Parera & mesmo & 23.04 .89 & $\begin{array}{l}\text { Cádiz } \\
15.08 .89\end{array}$ & $\begin{array}{l}\text { Barcelona } \\
07.10 .89\end{array}$ \\
\hline 14 & El Pinzón & $\begin{array}{l}\text { bergantim- } \\
\text { correio }\end{array}$ & Juan Fuso & Coroa & 27.04 .89 & $\begin{array}{l}\text { Coruña } \\
08.07 .89\end{array}$ & \\
\hline 15 & El Favorito & fragata & $\begin{array}{l}\text { Pedro Francisco } \\
\text { Noel }\end{array}$ & mesmo & 18.05 .89 & $\begin{array}{l}\text { Cádiz } \\
29.08 .89\end{array}$ & \\
\hline 16 & S. Juan Bauptista & saetia & $\begin{array}{l}\text { Feliciano } \\
\text { Carnesoltas }\end{array}$ & mesmo & 23.05 .89 & $\begin{array}{l}\text { Cádiz } \\
01.10 .89\end{array}$ & $\begin{array}{l}\text { Barcelona } \\
12.11 .89\end{array}$ \\
\hline 17 & N.S. de Gracia & bergantim & Jayme Tutzó & mesmo & 26.05 .89 & $\begin{array}{l}\text { Cádiz } \\
01.10 .89\end{array}$ & $\begin{array}{l}\text { Barcelona } \\
18.12 .89\end{array}$ \\
\hline 18 & El Águila & $\begin{array}{l}\text { fragata- } \\
\text { correio }\end{array}$ & Francisco Abello & Coroa & 10.06 .89 & $\begin{array}{l}\text { Coruña } \\
22.08 .89\end{array}$ & \\
\hline 19 & S.Juan Bauptista & saetia & $\begin{array}{l}\text { Mariano } \\
\text { Llauguer }\end{array}$ & mesmo & 17.06 .89 & $\begin{array}{l}\text { Cádiz } \\
26.10 .89\end{array}$ & $\begin{array}{l}\text { Barcelona } \\
25.01 .90\end{array}$ \\
\hline
\end{tabular}

Tomo LIII, 1, 1996 


\begin{tabular}{|c|c|c|c|c|c|c|c|c|}
\hline \multicolumn{2}{|c|}{$N^{o}$} & \multicolumn{2}{|c|}{ Embarcação } & \multicolumn{5}{|c|}{ Calendário da Viagem } \\
\hline & Nome & Tipo & Capitão & Propriedade & $\begin{array}{l}\text { Saída de } \\
\text { Montevideo }\end{array}$ & Entrada & Entrada & Entrada \\
\hline 20 & El Conde de Cifuentes & fragata & $\begin{array}{l}\text { Manuel Antonio } \\
\text { de Somarriva }\end{array}$ & $\begin{array}{l}\text { Vicente de } \\
\text { la Torre }\end{array}$ & 07.07 .89 & $\begin{array}{l}\text { Cádiz } \\
24.10 .89\end{array}$ & & \\
\hline 21 & S. Francisco de Paula & polaca & $\begin{array}{l}\text { Francisco } \\
\text { Marxuach }\end{array}$ & mesmo & 17.07 .89 & $\begin{array}{l}\text { Cádiz } \\
04.10 .89\end{array}$ & $\begin{array}{l}\text { Barcelona } \\
07.11 .89\end{array}$ & \\
\hline 22 & La Elisabet & $\begin{array}{l}\text { fragata } \\
\text { (inglesa) }\end{array}$ & $\begin{array}{l}\text { Francisco Xavier } \\
\text { de Zubízar }\end{array}$ & $\begin{array}{l}\text { fretada pela } \\
\text { Real Cia. } \\
\text { de Filipinas }\end{array}$ & 19.08 .89 & $\begin{array}{l}\text { Cádiz } \\
03.12 .89\end{array}$ & & \\
\hline 23 & La Infanta & $\begin{array}{l}\text { fragata- } \\
\text { correio }\end{array}$ & $\begin{array}{l}\text { Juan Antonio } \\
\text { Gonzalez }\end{array}$ & Coroa & 21.08 .89 & $\begin{array}{l}\text { Coruña } \\
11.11 .89\end{array}$ & & \\
\hline 24 & N. S. de Monserrate & bergantim & Francisco Mas & mesmo & 30.08 .89 & $\begin{array}{l}\text { Barcelona } \\
21.12 .89\end{array}$ & & \\
\hline 25 & La Dichosa & fragata & $\begin{array}{l}\text { Francisco de } \\
\text { Paula Enriquez }\end{array}$ & Ignacio Corallo & 09.09 .89 & $\begin{array}{l}\text { Cádiz } \\
27.01 .90\end{array}$ & & \\
\hline 26 & S. Francisco de Paula & bergantim & Francisco Rafuls & mesmo & 16.09 .89 & $\begin{array}{l}\text { Cádiz } \\
14.01 .90\end{array}$ & $\begin{array}{l}\text { Málaga } \\
05.02 .90\end{array}$ & \\
\hline 27 & N.S. de Monserrate & bergantim & Andres Fontanales & mesmo & 30.09 .89 & $\begin{array}{l}\text { Málaga } \\
06.02 .90\end{array}$ & $\begin{array}{l}\text { Barcelona } \\
09.04 .90\end{array}$ & \\
\hline 28 & El Colón & $\begin{array}{l}\text { fragata- } \\
\text { correio }\end{array}$ & Manuel & $\begin{array}{l}\text { Coroa } \\
\text { Fernandes Trelles }\end{array}$ & $\begin{array}{l}08.10 .89 \\
\text { s }\end{array}$ & Coruña & 05.12 .89 & \\
\hline 29 & El Valeroso Alejandro & fragata & $\begin{array}{l}\text { Francisco } \\
\text { Casimiro de Xado }\end{array}$ & $\begin{array}{l}\text { Francisco de } \\
\text { Xado y Castilho }\end{array}$ & 09.10 .89 & $\begin{array}{l}\text { Cádiz } \\
26.03 .90\end{array}$ & & \\
\hline 30 & N. S. del Carmen & bergantim & Luiz Barriga & mesmo & 17.10 .89 & $\begin{array}{l}\text { Málaga } \\
09.04 .90\end{array}$ & $\begin{array}{l}\text { Barcelona } \\
26.04 .90\end{array}$ & \\
\hline 31 & S. Joseph & bergantim & Joseph Coll & mesmo & 23.10 .89 & $\begin{array}{l}\text { Barcelona } \\
06.04 .90\end{array}$ & & \\
\hline 32 & S. Andres Avelino & bergantim & $\begin{array}{l}\text { Geronimo Matas } \\
\text { y Vinals }\end{array}$ & mesmo & 23.10 .89 & $\begin{array}{l}\text { Barcelona } \\
12.04 .90\end{array}$ & & \\
\hline 33 & La Vella Americana & bergantim & Manuel de Basabe & $\begin{array}{l}\text { Parraga } \\
\text { y Barandiaram }\end{array}$ & 06.11 .89 & $\begin{array}{l}\text { Santander } \\
02.03 .90\end{array}$ & & \\
\hline 34 & N. S . del Viñet & saetia & Sebastián Coll & mesmo & 28.11 .89 & $\begin{array}{l}\text { Cádiz } \\
17.04 .90\end{array}$ & $\begin{array}{l}\text { Málaga } \\
11.06 .90\end{array}$ & \\
\hline 35 & N. S. de la Asumpción & saetia & Buenaventura Ros & mesmo & 13.12 .89 & $\begin{array}{l}\text { Málaga } \\
09.05 .90\end{array}$ & & \\
\hline 36 & La Princesa & fragata-cor & & Pedro del Barco & Coroa & 17.12 .89 & $\begin{array}{l}\text { Coruña } \\
01.03 .90\end{array}$ & \\
\hline
\end{tabular}

